\title{
Correction to: Time Scales and Turbulent Spectra above the Base of Stirred Vessels from Large Eddy Simulations
}

\author{
Jason J. Giacomelli ${ }^{1,2} \cdot$ Harry E. A. Van den Akker ${ }^{2}$
}

Published online: 11 February 2020

(c) Springer Nature B.V. 2020

\section{Correction to: Flow, Turbulence and Combustion https://doi.org/10.1007/s10494-019-00095-z}

The correct Figs. 1, 3 and 4 are presented in this correction article. The original article has been corrected.

The original article can be found online at https://doi.org/10.1007/s10494-019-00095-z.

Jason J. Giacomelli

jgiacomelli@philamixers.com

1 Philadelphia Mixing Solutions Ltd, Palmyra, PA, USA

2 Bernal Institute, School of Engineering, University of Limerick, Limerick, Ireland 

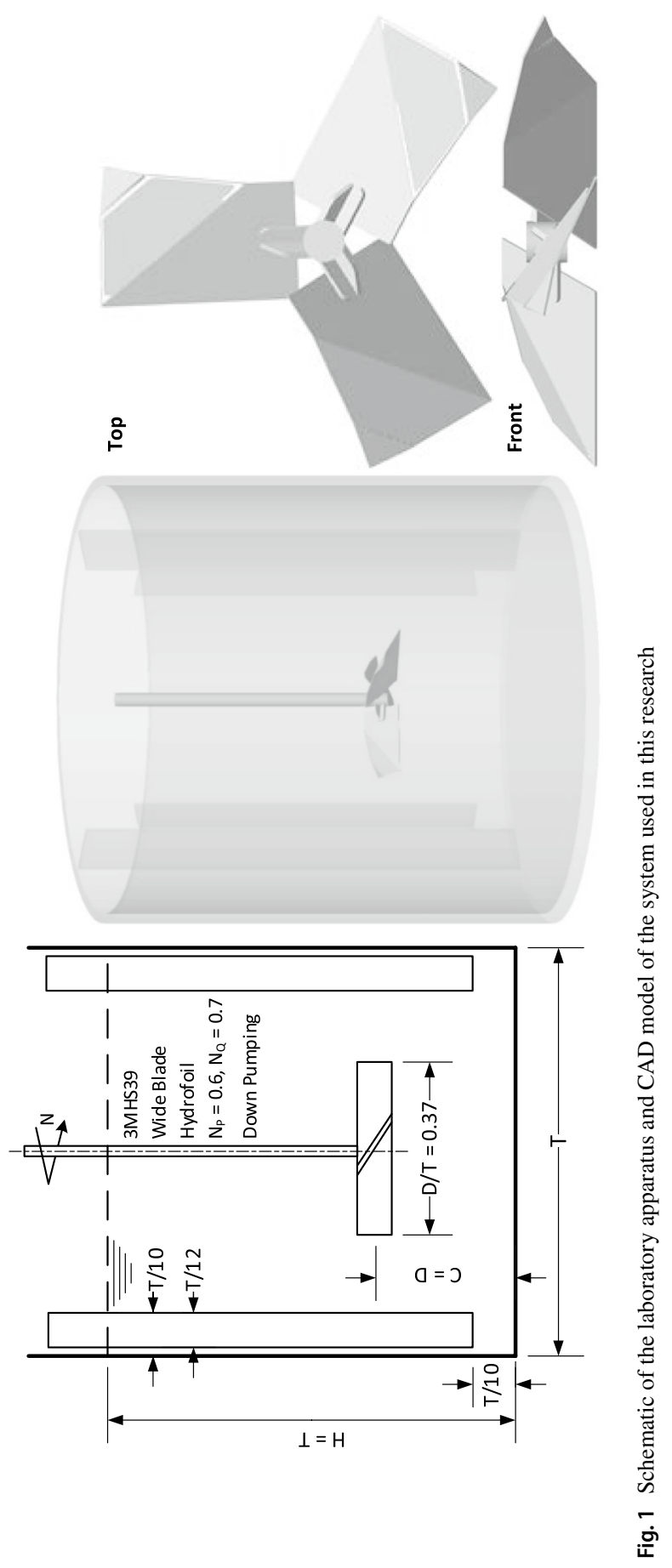

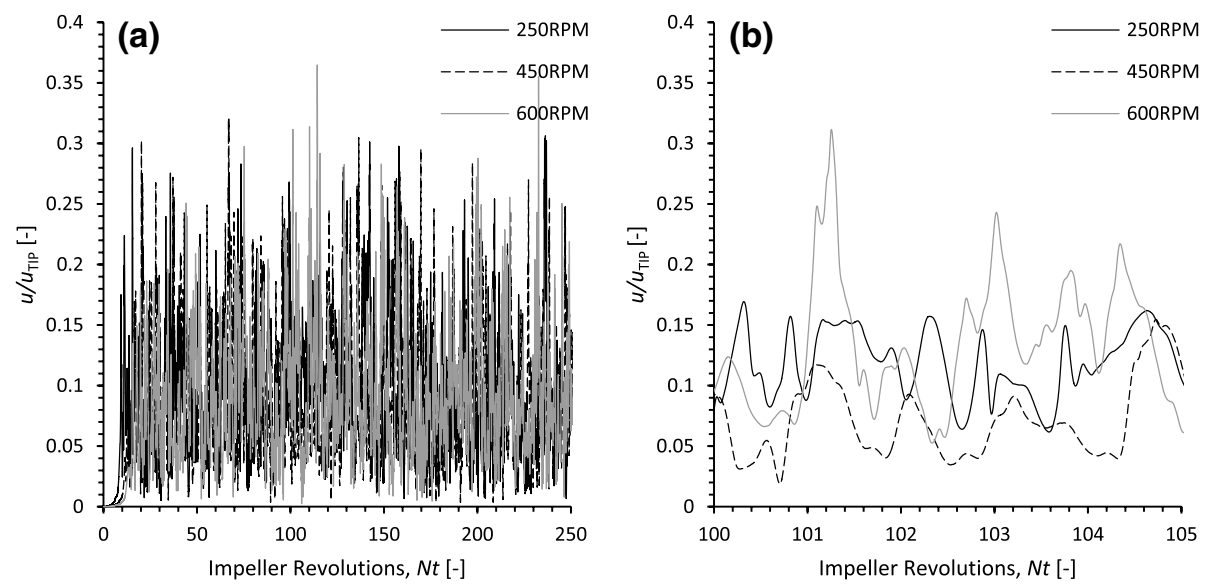

Fig. 3 Comparison of typical normalized velocity magnitude traces obtained from the Large Eddy Simulations. Examples from 250, 450, 600RPM obtained at the same probe location are shown. a Full simulation trace. b Zoom of trace between 100 and 105 impeller revolutions showing finer detail of fluctuations 

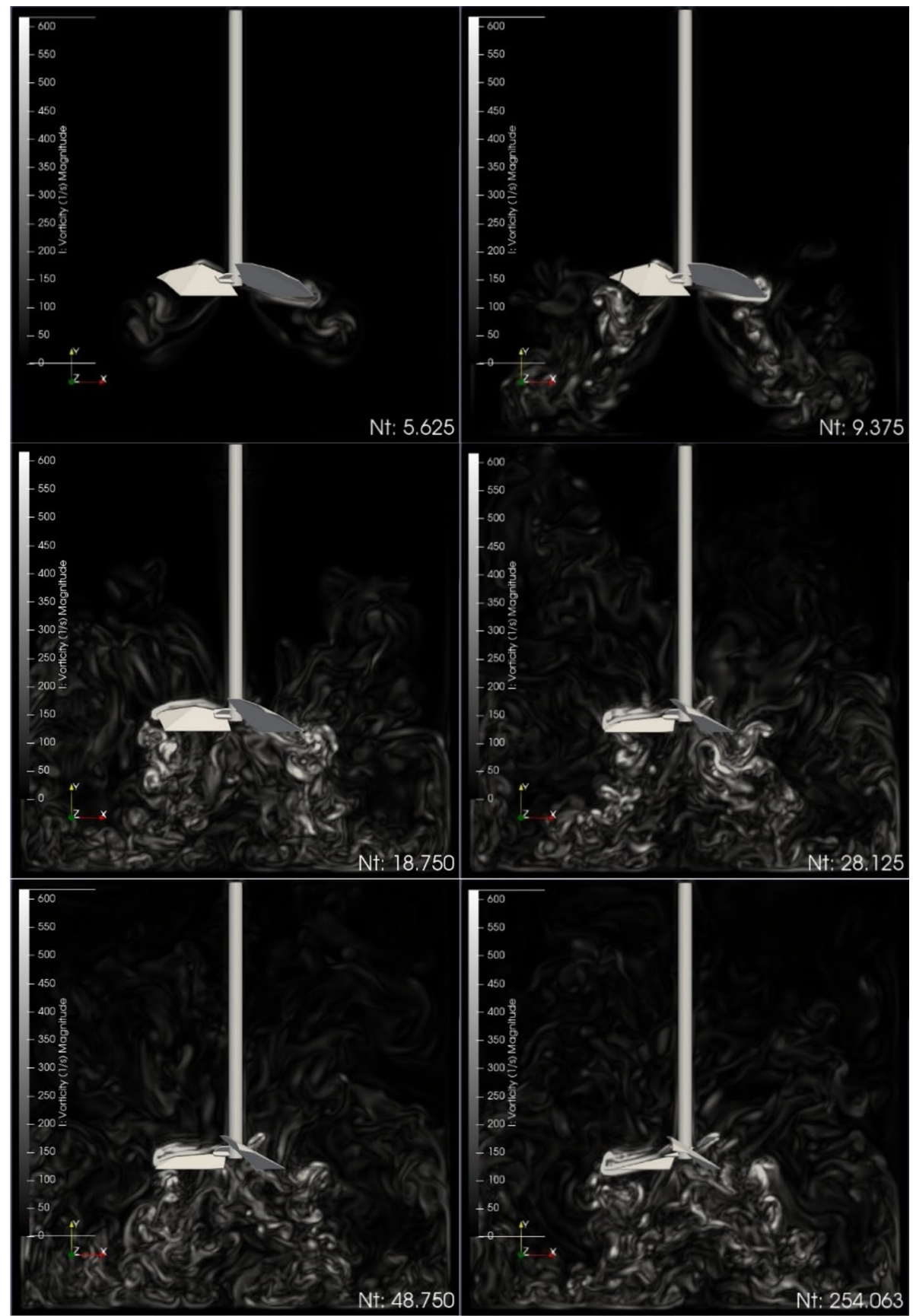

Fig. 4 Time evolution of instantaneous vorticity contour in the $x y$-plane at $z=0$, Case 3A, 450RPM, $0.174 \mathrm{~W} / \mathrm{kg}$. Time has been converted to number of impeller revolutions, $N t$ 